\title{
Pour comprendre les enjeux de la communication politique locale
}

\section{Maryse Souchard et Stéphane Wahnich}

\section{(2) OpenEdition}

12 Journals

Édition électronique

URL : http://journals.openedition.org/communicationorganisation/1739

DOI : 10.4000/communicationorganisation. 1739

ISSN : $1775-3546$

Éditeur

Presses universitaires de Bordeaux

Édition imprimée

Date de publication : 1 novembre 1994

ISSN : 1168-5549

\section{Référence électronique}

Maryse Souchard et Stéphane Wahnich, «Pour comprendre les enjeux de la communication politique locale », Communication et organisation [En ligne], 6 | 1994, mis en ligne le 26 mars 2012, consulté le 30 avril 2019. URL : http://journals.openedition.org/communicationorganisation/1739; DOI : 10.4000/ communicationorganisation. 1739

Ce document a été généré automatiquement le 30 avril 2019.

(c) Presses universitaires de Bordeaux 


\title{
Pour comprendre les enjeux de la communication politique locale
}

\author{
Maryse Souchard et Stéphane Wahnich
}

\section{RÉSUMÉS}

Cette note de recherche vise à poser la question d'une définition de la communication politique locale. Dans l'état actuel des réflexions sur cette question, il semble particulièrement important de pouvoir s'entendre sur une définition - qui reste encore trop floue dans l'ensemble des travaux spécialisés - pour pouvoir ensuite poser les enjeux de la communication politique locale.

This paper wants to think about a definition on what is communication in the local area. This kind of definition is really important - and it is not yet done in the theorical papers on the subject - to be able to discuss on the specificity of this kind of communication.

\section{AUTEURS}

\section{MARYSE SOUCHARD}

Stéphane Wahnich est diplômé de Sciences politiques et d'économie (Paris I Sorbonne). Il est le fondateur et le directeur de l'institut d'études et de sondages SCP Communication, spécialisé auprès des collectivités locales.

\section{STÉPHANE WAHNICH}

Ensemble, ils préparent actuellement un « Que Sais-je ? » sur La communication politique locale (à paraître en 1995) et ils sont chargés du séminaire « Les enjeux et les objectifs 
politiques de la communication locale » au DESS « Communication, politique et animation locales » du Département de Sciences politiques de l’Université Paris I Sorbonne. 